\title{
Research on Creative Industry Cluster, Knowledge Externality and Synergy Innovation
}

\author{
Cong-sheng Zhong \\ Business School of Tianjin University of Commerce \\ Tianjin, China \\ 775473323@qq.com
}

\author{
Ming-xian Wang, Jing Chen \\ Business School of Tianjin University of Commerce \\ Tianjin, China \\ wangmingxian03@126.com
}

\begin{abstract}
Based on the theory of industrial cluster and externality, this paper expounds the network characteristics, knowledge sharing and knowledge overflow of the creative industry cluster. From knowledge externality of creative industry cluster, the relationship between creative industry cluster and collaborative innovation had been studied. The result of research shows that the creative industry cluster can promote collaborative innovation ability by three ways which are tacit knowledge overflow of MAR externality, complementary knowledge sharing of Jacobs's externality and interactive learning mechanism of Porter's externality.
\end{abstract}

Keywords-The creative industry cluster; Knowledge externality; Collaborative innovation

\section{INTRODUCTION}

Creative industry is the engine of the regional collaborative innovation which fits characteristics of the knowledge economy era and integrates the creative thinking into the science and technology, and treats the abstract and intangible symbol originality as the source of the industrial chain. Creative industry is the activity to create wealth and potential employment based on the development of intellectual property rights ${ }^{[1]}$, the cluster is the integration of enterprises and institutions which relatively concentrated on the geographical location, it can form the advantage of industries and regional innovation. The development of creative industry cluster promotes the exchange of information, the talents convergence and the creative inspiration. Therefore, the key of creative industry cluster lies in knowledge sharing and spillover of the different knowledge source, and the different knowledge attributes in the process of the flow, and then affects the region's collaborative innovation and innovation performance. However, most of existing studies tend to examine the cluster effect and external effect itself through empirical approach, and there is little research on the impact mechanism of creative industry cluster and knowledge externality to collaborative innovation of by model and empirical study. Undoubtedly, the research has the vital significance on development of creative industry cluster and collaborative innovation.

\section{LITERATURE REVIEW}

\section{A. Creative industry cluster}

Michael Porter put forward that the cluster is a kind of phenomenon which related companies or institutions gathered in a specific geographical location in a particular industry, the cluster includes a series of downstream industries, and other enterprises or institutions, which are important for competition ${ }^{[2]}$. Creative industry cluster is a kind of development model of cultural creative industry, and a certain amount of creative enterprises concentrated in certain areas to form a certain industry scale. As the number of niche markets of design intensive and information intensive products is rising and cultural production is increasingly concentrated to some privileged enterprises and distinctive area, the general situation of the creative industry cluster arises. At home and abroad, a large number of theoretical deduction and empirical studies have confirmed that the unique attributes of creative industries make it tend to form a cluster development trend. Professor Scott analyzed the formation motivation of creative industries from two factors which are geographical proximity and high population density, at the same time, pointed out the network relations and symbiotic relationship between product cooperation and creative partner through the creative industry cluster ${ }^{[3]}$. Yusuf and Nabeshima studied connection degree, cyber-relation and network organization between the enterprises to participate in the creative industry cluster ${ }^{[4]}$ and proved the existence of network tie of the creative industry cluster.

Creative products, from creative source to the process of commercialization, strongly depends on fast acquisition, production, innovation, accumulation, dissemination, and application of consumption of the local implicit knowledge, thus to promote cultural creative enterprises and person to form the network connection system by learning and cooperation each other. Within the cultural creative industry cluster, creative behavior of the industry usually based on implicit knowledge, which isn't acquired unless by face-to-face and one-to-one communication. Creative products aren't applied and consumed unless more 
face-to-face, communication and guidance. Therefore, the informal networks formed between people become more crucial. In addition, various industry associations such as universities, research institutes, financial institutions, legal advisers, local governments etc, are bring together to provide the necessary talent, technology, policy and financial support for the creative industry, so as to form a formal network structure. In the network system, the action of information flow, knowledge sharing, knowledge complementation and knowledge overflow are acted in all kinds of behavioral agents by a formal or informal relationship (shown in Figure 1).

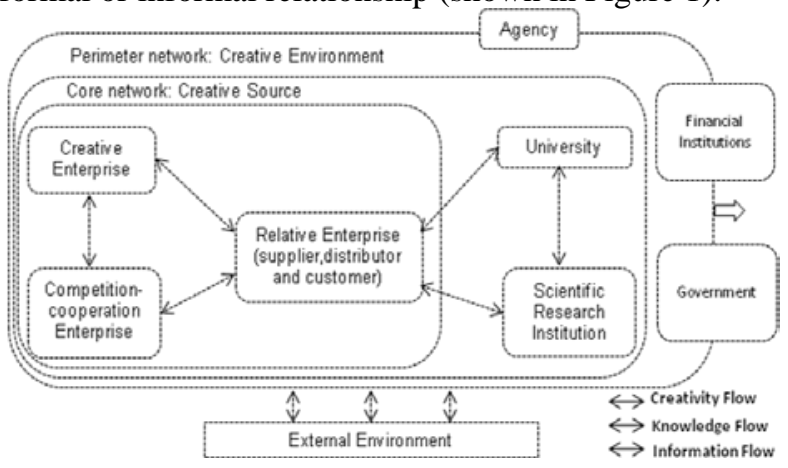

Fig. 1. The characteristics of network structure of creative industry cluster

\section{B. The knowledge externality of creative industry cluster}

Externality is one of the most important concepts in economics which is firstly used to interpret the phenomenon that enterprises centralize in the same location based on external economy. According to the types of cluster and the difference of external mechanism, MAR externalities ${ }^{[5]}$ (MAR Externality) ${ }^{[6]}$, Jacobs externality (Jacobs Externality) and Porter externalities ${ }^{[7]}$ are summarized.

MAR externalities (MAR Externality) pay attention to knowledge spillover between different enterprises within the same industry. Knowledge externality come from the gather of many enterprises in the same industry within a certain area, which contributes to knowledge spillover and knowledge diffusion between companies, and the specialization degree of industry is in favor of the generating of externality and the industrial innovation. Jacobs externalities (Jacobs Externality) emphasize that knowledge spillover derives from the outside of the core industry, and consider that cross-industry cluster can promote the overflow of enterprise knowledge, inter-industry diffusion of complementary knowledge, inter-industry synthesis of technology innovation. Then, Porter externalities consider that knowledge spillover mainly comes from different enterprise's competition within the same industry.

For the creative industries based on the cultural resources, originality derive from the deductive process of cultural knowledge, and creative industry product depends on the formation of a new cultural symbols and the recognition of cultural identity, so the process of creative industry cluster is the process of value cognition of knowledge externalities, and along with the production of economic externality of consumption; whether the
MAR externalities (MAR Externality) of creative industry cluster, or Jacobs externalities (Jacobs Externality) of creative industry cluster and the Porter Externality of competition between different enterprises, the creative industry cluster is closely related to the flow, overflow and sharing of knowledge. As a result, the overflow and sharing activity of knowledge of the creative industry cluster generates a lot of externalities, which provide opportunities of collaborative innovation for stakeholders.

\section{Creative industry cluster in collaborative innovation}

Collaborative innovation is the process of value creation from enterprises, scientific research institutes of universities, government and education department, the core is intellectual appreciation. Intellectual appreciation activities include the development of knowledge, knowledge acquisition, knowledge sharing and knowledge diffusion; and the process of collaborative innovation activities turns new knowledge into capital and forms the scale effect through interact of the innovative subjects. The key of collaborative innovation is to form network innovative model of multiple collaborative interaction subject which is based on the core elements, such as universities, enterprises research institutions and auxiliary elements, such as governments, financial institutions, intermediary organizations, innovation platform, nonprofit organization etc, and the ability and effect of collaborative innovation are promoted through in-depth cooperation and resource integration between the subject of knowledge creation and the subject of technology innovation ${ }^{[8]}$.

From the network structural characteristics of creative industry cluster, resource complementation from clustered enterprises is the core for cross-border collaborative innovation ${ }^{[9]}$. By gathered various external-relationship of partners, enterprises can get technology, professional knowledge, business network, intellectual property and so on ${ }^{[10]}$, and achieve collaborative innovation through sharing and overflow of external intelligence resource from the outside of enterprise.

\section{THE COLLABORATIVE INNOVATION INFLUENCE MECHANISM OF CREATIVE INDUSTRY CLUSTER BASING ON INTERMEDIARY OF KNOWLEDGE EXTERNALITIES}

With development of knowledge economy, the speed of knowledge updating of creative industries is accelerated constantly. Fast updating knowledge not only requires the enterprise to have the unique knowledge and ability, but also to continue to absorb and digest external knowledge, to achieve collaborative innovation through complementation and fusion with external knowledge. The creative industry cluster provides regional space of information sharing and knowledge flowing for creative enterprises of different industries, universities, research institutes, intermediary organizations etc, and different knowledge externalities also provide a different collaborative innovation path for cross-organizational collaborative innovation. 
A. Creative industry cluster and collaborative innovation basing on MAR externalities of axis

MAR externalities believe that knowledge spillover exists enterprises within industry, tacit knowledge spillover from the creative industry in the particular location also enhance the collaborative innovation ability in the cluster area.

Due to the geographical proximity, the collision between enterprise and enterprise become more convenient and quicker, and a variety of information and knowledge within the collision also can spread quickly in creative industry cluster. The knowledge core of creative industry is tacit knowledge, and product association and asset correlation as the most important resource element giving way to knowledge association. In the knowledge system of creative industries, tacit knowledge is the core and the most important knowledge, creative industry cluster exist significant effect of tacit knowledge spillover. Creative industry cluster provides good atmosphere for member enterprise to acquire all kinds of tacit knowledge quickly and conveniently. Creative enterprises acquire tacit knowledge through formal and informal communication between human resources in the cluster area, and finally form the regional knowledge creation (tacit knowledge) through the digestion, absorption and integration. Due to overflow of tacit knowledge, the innovative activity which is characterized by learning among partners and creating knowledge enhance the collaborative innovation capability of creative industry cluster.

B. Creative industry cluster and collaborative innovation basing on Jacobs externalities of axis

Jacobs externalities through the collision of different thinking and the exchange of complementary knowledge between enterprises and organizations in different industries to improves the collaborative innovation capability of the cluster area.

Industry value chains exist between the upstream and downstream enterprises associated with the creative industries. The relationship among various business units within enterprises consist the value chains of enterprise. There are also value chains exist business units within enterprises. Creative activity is the core for creative industry, the creative thinking will be converted directly into commodities with high economic value in virtue of science and technology. Adding value of value chain of creative industry means the innovative ability of creative enterprise is strong. In the operational process of the value chain of creative industries, collaborative innovation is not only concerned about the realization of the value through a one-way product delivery, but pays more attention to derivative products and creates value with customers and stakeholders. In the industry value chain of creative industry cluster, therefore, any upstream enterprise can regard customers as a key link in the value network. Interaction with customers is regarded as a kind of resource for realization of enterprise collaborative value. Due to the sharing of complementary resources, upstream and downstream enterprises, the partnership based on resource dependency and collaborative trust are formed in creative industry cluster, it is the value alliance. The value alliance of collaborative innovation makes the innovation resources of industry cluster gradually accumulated and the advantages of innovation developed.

\section{Creative industry cluster and collaborative} innovation basing on Porter externalities of axis

Porter externalities mean the different industries and the same industries are existed in the creative industry cluster. The behavior subjects of creative industry cluster are changed through the interaction between these enterprises and organizations, and the process of these changes also promotes the ability of cooperative innovation in the cluster area.

The essence of collaborative innovation is an innovative organization model of the large span integration to achieve major scientific and technological innovation, it includes enterprises, government, knowledge production institutions (universities, research institutions), intermediary organizations and users. When the behavior subject of creative industry cluster provides services, it can communicate with the creative enterprises clearly and effectively and form an integrated service provider, so as to get the work innovate. The innovation resources of creative industries not only include technical knowledge related with industries, capital, talent, information and other resources, but also include national science and technology resources, basic condition platform and service system for the realization of industrial technology innovation. There are various organizations, such as government agencies, industry associations, universities, associations and all kinds of professional service organizations in the creative cluster. They provide creative cluster enterprises resources collaboration, such as policy guidance, market information, technical support, management and consulting, personnel training, market development and so on in the process of cluster interaction, and to achieve the optimal matching and the maximum utility value of resource, and gradually form collaborative innovation network model of multi-agent cooperative interaction basing on the core elements of universities, enterprises, research institutions, and the auxiliary elements of the government, financial institutions, intermediary organizations, innovative platforms, non-profit organizations etc.

\section{THE CONCLUSION AND PROSPECT}

Creative industry cluster gathers characteristics of network characteristics, knowledge sharing and knowledge overflow. Enterprises or organizations in accumulation area can get cluster external effect of knowledge sharing and knowledge spillover produced by MAR externalities, Jacobs externalities and Porter externality, so as to promote collaborative innovation activities in the cluster district. 
From the perspective of knowledge externalities of creative industry cluster, collaborative innovation ability of accumulation areas can be improved through three ways. Firstly, the tacit knowledge spillover caused by the MAR externalities of creative industry cluster enhances the synergy innovation ability of creative industry cluster; Secondly, the complementary knowledge sharing caused by Jacobs externalities of creative industry cluster enhances the synergy innovation ability of creative industry cluster; Thirdly, the interactive learning mechanism caused by Porter of creative industry cluster externalities enhances the synergy innovation ability of creative industry cluster.

From the perspective of network characteristics of creative industry cluster, the externality of knowledge of creative industry cluster is analyzed and the theory of mechanism about creative industry cluster- cluster of knowledge externalities- ability enhancing of the regional collaborative innovation is clarified, it establishes theoretical foundation for the further empirical research.

\section{ACKNOWLEDGMENT}

This paper is one of the stage achievements of art planning in Tianjin that a study on the cultural creative industry cluster, externalities and collaborative innovation mechanism (E12063), philosophy and social science research planning project in Tianjin that a study on regional innovation performance evaluation based on the background of Tianjin Free Trade Zone (TJYY15-028), and a study on the current situation, problems and related policies of innovation method promotion in Tianjin Binhai New District (TJGL12-044).

\section{REFERENCES}

[1] Lawson C, Lorenz E.Collective Learning, Tacit Knowledge and Regional Innovative Capacity[J].Regional Studies, Jun.1999,33:305 -317.

[2] Scott A. J. Cultural-Products Industries and Urban Economic Development- Prospects For Growth and Market Contestation In Global Context[J].Urban Affairs Review,2004( 4) : 461-490.

[3] Wu,W. Dynamic Cities and Creative Clusters[Z]. World Bank Policy Research Working Paper 3509,Washington DC,2005.

[4] Allen Scott,Entrepreneurship,Innovation and Development;Geography and the Creative Field Revisited[J].Small Business Economics,2006,26:1-24.

[5] Marshall A.(1920), Principles of Economics. 8th ED , London: Macmillan \& Co, 1920, P. 241-266.

[6] Jacobs. J. , The Economy of Cities, New York: Random House, 1969.

[7] Porter. M. , The competitive advantage of nations, New York: Free Press, 1990.

[8] Vuola O, Hameri A P. Mutually benefiting joint innovation process between industry and big-science[J].Technovation, 2006, 26( 1) : 3-12.

[9] Schwartz M, Peglow F, Fritsch $M$, etal. What drives innovation output from subsidized $\mathrm{R} \& \mathrm{D}$ cooperation? -Project-level evidence from Germany [J].Technovation,2012,32(6): 358-369.

[10] Fu L, Zhou X, Luo Y. The research on knowledge spillover of industry-university-research institute collaboration innovation network [C].The 19th International Conference on Industrial Engineering and Engineering Management. Berlin: Springer Berlin Heidelberg, 2013: 361-371. 